\title{
US health agencies at odds over trial deaths
}

Washington. Clinical trials last spring by the US National Institutes of Health (NIH) of the drug fialuridine, in which five patients died of liver failure, were carried out "with no noteworthy flaws", according to a panel of external scientists appointed by the (NIH) to investigate the tragedy.

The panel's report, submitted last week to Harold Varmus, the director of NIH, says that the studies were well designed, conducted and monitored, and that careful attention was paid to patient symptoms. "There were no errors in clinical judgement or the research process," the report says.

But the findings of the panel, which was jointly chaired by David Challenor, vicepresident of the University of Florida, and David Kipnis of Washington University, St Louis, Missouri, conflict sharply with those of a parallel investigation by the Food and Drug Administration (FDA).

Last month, the FDA sent severely worded warning letters to Jay Hoofnagle, the principal investigator, and others in- volved in the trials - including their sponsor, Eli Lilly of Indianapolis - alleging lax reporting of patients' symptoms and flawed procedures for gaining their informed consent (see Nature 369, 268;1994).

The five patients died suddenly during the third trial, which was abandoned. Subsequent investigation revealed that at least one patient on an earlier safety trial had died the same way, but the death had been attributed to the patient's illness, not to side-effects of the drug.

The NIH panel spent six months examining the reasons for the three NIH fialuridine studies, how well they were conducted, how the institutes responded to problems with the trials, and whether the five deaths from liver failure on the third study could have been avoided.

It found that there was "a justifiable scientific rationale" for all the studies, and that the research team's progression from the first study, carried out on HIV-positive patients, to the two later ones on patients

\section{'Irreproducible' team clones a rival}

San Francisco. The American staff of The Journal of Irreproducible Results (JIR), the oldest and best-known satirical science journal, have left to set up a competing magazine after several years of disagreements with its British publisher. The 40 -member board of scientists, which includes seven Nobel prizewinners, went with them.

The first electronic issue of the new Annals of Improbable Research (AIR), including news of what it described as the "revolt of the mad scientists", appeared on the Internet last week. The first paper edition is expected in the autumn.

But Jon Conibear, deputy managing director of Blackwell Scientific Publications in Oxford, England, which publishes $J I R$, denies claims that the future of the original journal is uncertain beyond the next edition. "The journal will continue to be published as before," he says, claiming that the launch of $A I R$ is not seen as a threat to $J I R$.

According to editor Mark Abrahams, the split is the result of long-lived antagonism with Blackwell. "It made them very uncomfortable that, of all the journals they published, this one was intentionally funny," says Abrahams, who claims that a largely volunteer staff was carrying out all marketing and publicity for the journal with no help from Blackwell.

"It finally seemed clear to us that there was no reasonable way we could either improve that situation or buy the rights to the name," says Abrahams.
"We all therefore decided to do the only reasonable thing: start a new magazine - one that has no legal connection to the magazine we left behind, on which we all worked so hard and loved so much."

But Conibear says that Abrahams was asked to leave as a result of irreconcilable editorial differences with $J I R$ 's Chicago-based owner George Sherr. Ownership of $J I R$ is due to revert back to Sherr after the June issue. Sherr is expected to announce a replacement editor later this month.

JIR was founded in 1955 by Alex Kohn, a virologist at Tel Aviv University, best known for his scientific paper proving that the North American continent is likely to sink under the accumulated weight of stockpiled National Geographic Society magazines. He eventually sold the rights to $J I R$, but remained as editor until 1989, when Abrahams took over. He and Abrahams are the co-founders of $\boldsymbol{A I R}$.

At the time of the revolt, $J I R$ had a circulation of 17,000 , including the electronic issue. Abrahams claims that it was once as high as $\mathbf{4 0 , 0 0 0}$, although Conibear disputes this figure.

The new publication takes with it the infamous Ig Nobel Awards, given out each year to people whose achievements in science "cannot or should not be reproduced". The awards ceremony will henceforth be sponsored jointly by $A I R$ and the Massachusetts Institute of Technology Museum, where the award ceremony takes place. Joel Shurkin with hepatitis B, was "justifiable and appropriate at the time".

The fialuridine studies, it says, "represent the best of current practice in clinical investigations and exceeded regulatory requirements where such applied". The NIH response to the liver failures on the third trial "was entirely appropriate and swift, in accordance with the highest standards of patient care"

Critics of the trial have questioned the independence of the panel, which reported to the NIH director's advisory committee. "You can't trust self-investigations," says Sidney Wolfe, a former NIH researcher who works with the Washington pressure group Public Citizen. Congressman Ed Towns (Democrat, New York), chairman of the House of Representatives subcommittee on human resources and intergovernmental relations, called the report a "whitewash".

But members of the seven-strong panel - six of them senior professors from US medical schools - point out that their professional reputations were at stake. "We were all ready to go public with bristling criticism if it was warranted," says Richard Corlin, a Californian physician.

Kipnis says that Varmus had made it clear to the panel that its task was to find out the facts and report them. "Any suggestion of whitewash would be offensive to every individual on the panel."

NIH panel members characterize the FDA investigation process as primarily an audit of figures, charts and times which has, for example, pinpointed minor discrepancies in the reporting of symptoms, even though they were not material to the tragic outcome of the third trial.

But Jim O'Hara, a spokesman for the FDA, points out that the agency talked to the investigators and the sponsors, as well as looking at the data. "We issued compliance letters because we believe there to have been significant violations of our regulations, and we stand by our letters," says O'Hara.

The NIH panel acknowledged that the two studies came to "apparently different conclusions", but says the FDA ignored repeated requests for a copy of its unpublished audit of the trials. The FDA has given Hoofnagle and Eli Lilly until 29 June to respond in detail to its warning letters.

The high profile of the fialuridine case, and the appearance of various overblown accounts on television and in Congress, has done little to ease long-standing tensions between the two federal agencies. But the impasse may be broken in six months' time when the Institute of Medicine delivers its verdict on the fialuridine case to the cabinet member responsible for both agencies, Donna Shalala, the Secretary of Health.

Colin Macilwain 